\title{
ANALISIS FAKTOR-FAKTOR YANG MEMPENGARUHI KONTRIBUSI WANITA PENYADAP KARET TERHADAP PENDAPATAN KELUARGA
}

(Studi Kasus Di Desa Sawang Lebar Kecamatan Air Napal Kabupaten Bengkulu Utara)

\author{
ANALYSIS OF THE FACTORS THAT INFLUENCE THE CONTRIBUTION OF \\ WOMEN BUGGING DEVICE RUBBER AGAINT THE INCOME \\ (A Case in Desa Sawang Lebar Kecamatan Air Napal Kabupaten Bengkulu Utara)
}

\author{
Rika Dwi Yulihartika, Herri Fariadi \\ Program Studi Agribisnis, Fakultas Pertanian , UNIVED
}

\begin{abstract}
RINGKASAN
Wanita dalam rumah tangga memiliki potensi untuk memberikan kontribusi terhadap pendapatan keluarga. Penelitian ini bertujuan untuk mengetahui kontribusi wanita penyadap karet terhadap pendapatan keluarga, yang dilihat dari alokasi waktu kerja, pendapatan, pendidikan, jumlah tanggungan keluarga, lama bekerja dan umur wanita penyadap karet. Jenis penelitian ini adalah kuantitatif. Populasi dan sampel dalam penelitian ini adalah wanita penyadap karet di Desa Sawang Lebar Kec. Air Napal Kab Bengkulu Utarayaitu sebanyak 45 orang. Penentuan sampel ditentukan dengan metode sampling total. Penelitian dianalisis melalui analisis regresi linear sederhana dan regresi linear berganda.

Hasil analisis regresi linear sederhana antara alokasi waktu kerja wanita penyadap karet terdapat pengaruh yang signifikan terhadap pendapatan keluarga, yaitu sebesar 59\%, antara pendapatan wanita penyadap karet terhadap pendapatan keluarga berpengaruh sebesar $54 \%$. Tingkat pendidikan berpengaruh signifikan terhadap pendapatan keluarga, yaitu sebesar $50 \%$. Jumlah tanggungan wanita penyadap karet terdapat pengaruh yang signifikan terhadap pendapatan keluarga, yaitu sebesar 26\%. Lama bekerja wanita penyadap karet tidak terdapat pengaruh yang signifikan terhadap pendapatan keluarga. Umur wanita penyadap karet tidak terdapat pengaruh yang signifikan terhadap pendapatan keluarga. Hasil analisis regresi linear berganda mengidentifikasi bahwa secara bersama-sama alokasi waktu kerja, pendapatan wanita penyadap, pendidikan, jumlah tanggungan keluarga, lama bekerja dan umur berpengaruh terhadap variabel dependent yaitu pendapatan keluarga, sebesar sebesar $69 \%$.
\end{abstract}

Kata Kunci: Kontribusi, alokasi waktu, pendapatan, pendidikan, jumlah tanggungan, lama bekerja, umur dan pendapatan keluarga wanita Penyadap Karet

\section{Abstrak}

Women in households has the potential to contribute to the family income. This study aims to determine the contribution of women to the family income of rubber tappers, as seen from the allocation of work time, income, education, number of dependents, length of service and age of the woman rubber tapper. This type of research is quantitative. Population and sample in this study were women rubber tappers in the village Width Sawang district. Air Napal Utarayaitu Bengkulu Regency as many as 45 people. The samples were determined by total sampling method. The study analyzed through the simple linear regression analysis and multiple linear regression.

Results of linear regression analysis between work time allocation woman rubber tapper there is a significant effect on household income, which amounted to 59\%, between revenue 
woman rubber tapper to the family income effect of 54\%. Significant effect on the education level of family income, which amounted to 50\%. Number of dependents woman rubber tapper there is a significant effect on household income, which amounted to 26\%. Old working woman rubber tapper was not a significant difference to the family income. Age woman rubber tapper was not a significant difference to the family income. The results of multiple linear regression analysis identified that together the allocation of work time, income tapper women, education, number of dependents, length of service and age affect the dependent variable that family income, amounting to about $69 \%$.

Keyword : Countribution, Allocation time, income ,education, dependants,

\section{PENDAHULUAN}

\section{Latar Belakang}

Perekonomian sebuah keluarga sangat dipengaruhi oleh pendapatan keluarga, yang bersumber dari pendapatan kepala keluarga atau suami. Namun pada kondisi saat ini, istri juga berkontribusi bagi pendapatan keluarga. Anggapan bahwa kaum perempuan selayaknya mengurus rumah tangga dan keluarga, sementara kaum pria diharapkan lebih banyak berperan di sektor publik, di tepis oleh Elizabeth (2007) yang menyatakan bahwa wanita sekarang tidak lagi menjadi teman hidup saja atau mengurus rumah tangga, tetapi ikut serta dalam menciptakan ketahanan ekonomi rumah tangganya. Sumarsono, dkk (1995), mengatakan bahwa peran perempuan dalam menopang kehidupan dan penghidupan keluarga semakin nyata. Mereka tidak saja bekerja mengurus keluarga tetapi sudah banyak yang bekerja di luar rumah sebagai pekerja di sektor formal maupun informal.
Salah satu kegiatan sektor informal adalah penyadap karet. Penyadap karet adalah orang yang mengambil getah dari pohon karet dengan menoreh kulit atau memangkas mayang atau akar. Bekerja sebagai ibu rumah tangga adalah sebuah keharusan bagi istri pada rumah tangga wanita penyadap karet yang dituntut agar dapat berperan ganda dalam rumah tangganya, dengan mengalokasikan waktu sehingga dapat meningkatkan pendapatan dalam rumah tangganya. Faktor-faktor yang berpengaruh adalah seperti umur, tingkat pendidikan, jam kerja, sifat pekerjaan, lama bekerja dan jumlah tanggungan terhadap pendapatan keluarga (Sudarmi, 2006).

Pendapatan wanita mempengaruhi pendapatan keluarga, pada umumnya wanita terdorong untuk mencari nafkah karena tuntutan ekonomi rumah tangga. Pendapatan suami saja belum dapat mencukupi kebutuhan keluarga yang senantiasa meningkat sedangkan pendapatan riil tidak meningkat. Oleh 
karena itu, terlihat bahwa wanita memberikan sumbangan yang besar terhadap pendapatan rumah tangga (Fauzia dalam Vitriawati, 2005).

\section{Rumusan Masalah}

Apakah curahan waktu kerja, pendapatan wanita penyadap karet, pendidikan, jumlah tanggungan, lama bekerja dan umur wanita penyadap karet secara bersama-sama berpengaruh terhadap pendapatan keluarga di Desa Sawang Lebar Kecamatan Air Napal Bengkulu Utara.

\section{Tujuan}

Untuk mengetahui pengaruh curahan waktu kerja, pendapatan wanita penyadap karet, pendidikan, jumlah tanggungan, lama bekerja dan umur wanita penyadap karet secara bersama-sama berpengaruh terhadap pendapatan keluarga di Desa Sawang Lebar Kecamatan Air Napal Bengkulu Utara.

\section{METODE PENELITIAN}

\section{Pemilihan Lokasi Penelitian}

Lokasi Penelitian dilakukan di Desa Sawang Lebar Kecamatan Air Napal Kabupaten Bengkulu Utara. Dipilihnya desa ini sebagai tempat penelitian karena di Desa Sawang Lebar Kecamatan Air Napal Kabupaten Bengkulu Utara terdapat perkebunan karet rakyat yang para penyadap karetnya mayoritas adalah wanita.

\section{Teknik Penentuan Sasaran dan Informasi Penelitian}

Populasi dalam penelitian ini adalah wanita penyadap karet di Desa Sawang Lebar Kecamatan Air Napal Kabupaten Bengkulu Utara. Berdasarkan data Kepala Desa, populasi wanita penyadap karet adalah sebanyak 45 orang. Penentuan sampel ditentukan dengan metode sampling total, yaitu suatu teknik pengambilan sampel dimana seluruh populasi dijadikan sampel (Arikunto, 2005). Sehingga semua wanita penyadap karet di Desa Sawang Lebar Kecamatan Air Napal Kabupaten Bengkulu Utara adalah menjadi sampel yaitu sebanyak 45 orang.

\section{Teknik Pengumpulan Data}

Data yang digunakan dalam penelitian ini adalah data primer dan data sekunder. Data primer diperoleh dari hasil wawancara langsung dengan para penyadap karet wanita yang dijadikan responden dengan menggunakan daftar pertanyaan (kuesioner). Data sekunder diperoleh dari data yang sudah ada sebelumnya. Data ini akan diperoleh dari kantor-kantor dan instansi yang erat kaitannya dengan penelitian ini. 
Teknik pengumpulan data yang digunakan oleh peneliti adalah :

\section{Observasi Lapangan}

Teknik observasi lapangan ini bertujuan agar peneliti dapat melakukan pengamatan langsung mengenai keadaan umum objek yang akan diteliti sehingga mendapatkan data yang diperlukan untuk kegunaan penelitian (Sugiyono, 2012). Dalam meneliti pengaruh alokasi waktu kerja, pendapatan, pendidikan, jumlah tanggungan dan umur wanita penyadap karet terhadap pendapatan keluarga di Desa Sawang Lebar Kecamatan Air Napal Kabupaten Bengkulu Utara.

\section{Kuesioner}

Kuesioner adalah teknik pengumpulan data melalui penyebaran seperangkat daftar pertanyaan atau pernyataan yang harus diisi oleh responden yang menjadi anggota sampel penelitian. Bentuk kuesioner yang digunakan berupa kuesioner terbuka dimana responden langsung menjawab pertanyaan yang tersedia dan dianggap sesuai dengan pertanyaan dan penyataan (Sugiyono, 2012:134)

\section{Dokumentasi}

Menurut Arikunto (2006) dokumentasi yaitu mencari data mengenai hal-hal atau variabel yang berupa catatan, transkip, buku, surat kabar, majalah, prasasti, notulen rapat, agenda dan sebagainya, jadi dokumentasi adalah metode pengumpulan data yang dilakukan dengan meneliti bahan dokumentasi yang ada dan mempunyai relevansi dengan tujuan penelitian.

\section{Analisis Data}

Jenis penelitian ini adalah kuantitatif, yang bertujuan untuk mengungkapkan suatu masalah, keadaan, peristiwa sebagaimana adanya atau mengungkap fakta secara lebih mendalam (Sugiyono 2012). Penelitian kuantitatif adalah suatu metode yang berupaya untuk mengunggapkan secara tepat sifat-sifat suatu individu atau kelompok tertentu atau mencantumkan frekuensi dan penyebaran suatu gejala dan adanya pengaruh tertentu yang bertujuan untuk mendeskripsikan variabel-variabel penelitian (Arikunto, 2002:262), dan mencari pengaruh antara satu variabel dengan variabel lainnya yang dapat dinyatakan dengan regresi. variabel penelitian adalah alokasi waktu kerja, pendapatan wanita penyadap karet, pendidikan, jumlah tanggungan, lama bekerja dan umur wanita penyadap karet. Untuk mengetahui kontribusi antara variabel alokasi waktu kerja $\left(\mathrm{X}_{1}\right)$, pendapatan penyadap karet $\left(\mathrm{X}_{2}\right)$, pendidikan penyadap karet $\left(\mathrm{X}_{3}\right)$, jumlah tanggungan keluarga $\left(\mathrm{X}_{4}\right)$, lama bekerja $\left(\mathrm{X}_{5}\right)$ dan umur wanita penyadap karet $\left(\mathrm{X}_{6}\right)$ secara bersama-bersama terhadap variabel pendapatan keluarga (Y) maka dilihat dari 
besarnya pengaruh variabel $\mathrm{X}$ secara bersama-bersama terhadap pendapatan keluarga (Y) dengan menggunakan analisis regresi linear berganda, adapun rumusnya sebagai berikut :

$$
\begin{aligned}
Y=a+b_{1} X_{1} & +b_{2} X_{2}+b_{3} X_{3 .} b_{4} X_{4}+b_{5} X_{5} \\
& +b_{6} X_{6} \ldots .+e
\end{aligned}
$$

Keterangan :

$$
\begin{array}{ll}
\mathrm{Y} & =\text { Variabel terikat } \\
\mathrm{a} & =\text { Konstanta } \\
\mathrm{b}_{1}, \mathrm{~b}_{2} \ldots \mathrm{b}_{6} & =\text { Koefisien dari X1, X2 } \\
\text { dan X3 } & \\
\mathrm{X}_{1}, \mathrm{X}_{2} \ldots \mathrm{X}_{6} & =\text { Variabel bebas } \\
\mathrm{e} & =\text { Kesalahan pengganggu }
\end{array}
$$

Untuk mengetahui apakah variabelvariabel bebas secara keseluruhan bersama-sama berpengaruh terhadap variabel terikat pada tingkat keperluan tertentu maka dilanjutkan uji-F pada taraf kepercayaan 95\%. Uji-F dapat dirumuskan sebagai berikut

$$
F=\frac{R^{2}(k-1)}{\left(1-R^{2}\right) /(n-k)}
$$

Keterangan :

$\mathrm{R}^{2}=$ koefisien determinasi

$\mathrm{k} \quad=$ jumlah variabel yang diamati (dependen dan variabel independent)

$\mathrm{n}$ = Jumlah Sampel

Adapun kriteria uji-F adalah sebagai berikut :
1. Jika $F_{\text {hitung }}>F_{t} t_{\text {tabel }}$ maka tolak Ho dan terima $\mathrm{Ha}$, artinya secara bersamasama variabel bebas berpengaruh terhadap variabel terikat.

2. Jika $F_{\text {hitung }}<\mathrm{t}_{\text {tabel }}$ maka terima Ho dan tolak Ha, artinya secara bersama-sama variabel bebas tidak berpengaruh terhadap variabel terikat.

Untuk mengetahui pengaruh masingmasing variabel bebas terhadap variabel terkait ditentukan uji-t dengan hipotesis sebagai berikut :

$$
\begin{aligned}
& \text { Ho : bi }=0 \\
& \text { Hi : bi }>0 \text { atau bi }<0
\end{aligned}
$$

bi

$$
\text { t hitung }=\frac{}{\text { Sbi }}
$$

Dimana :

bi $\quad$ : Koefisien Variabel Xi

I $\quad: 1,2,3 \ldots 6$

Sbi : Kesalahan baku koefisien bi

Adapun kriteria pengujiannya adalah sebagai berikut :

a. Jika $t_{\text {hitung }}>t_{\text {tabel }}$, atau $-t_{\text {hitung }}<-t_{\text {tabel }}$ maka tolak Ho dan terima Ha, artinya secara individu variabel bebas berpengaruh terhadap variabel terikat.

b. Jika $t_{\text {hitung }}<t_{\text {tabel}}$, atau $-t_{\text {hitung }}>-t_{\text {tabel }}$ maka terima Ho dan tolak Ha, artinya secara individu variabel bebas tidak berpengaruh terhadap variabel terikat 
HASIL DAN PEMBAHASAN

\section{Uji Validitas}

Uji validitas digunakan untuk mengetahui kalayakan butir-butir dalam suatu daftar pertanyaan dalam mendefinisikan suatu variabel, yang pada umumnya mendukung suatu kelompok variabel tertentu. Hasil uji validitas pada output SPSS dapat dilihat pada tabel 1 .

Jika r-hitung lebih besar dari r-tabel maka dikatakan valid. Berikut adalah hasil uji validitas yang dilakukan :

a. Pendapatan keluarga, nilai $0.738>$ 0.304 , kesimpulan valid

b. Alokasi waktu kerja, nilai $.0 .810>$ 0.304 , kesimpulan valid

c. Pendapatan wanita penyadap karet, nilai $0.738>0.304$, kesimpulan valid

d. Pendidikan wanita penyadap karet, nilai $0.733>0.304$, kesimpulan valid e. Jumlah Tanggungan wanita penyadap karet, nilai $0.490>0.304$, kesimpulan valid

f. Lama Bekerja wanita penyadap karet, nilai $0.249<0.304$, kesimpulan tidak valid

Umur wanita penyadap karet, nilai $0.211<0.304$, kesimpulan tidak valid

\section{Uji Realibilitas}

Realibilitas (Keandalan) merupakan ukuran suatu kestabilan dan konsistensi responden dalam menjawab hal yang berkaitan dengan konstruk-konstruk pertanyaan yang merupakan dimensi suatu variabel yang disusun dalam suatu bentuk kuesioner. Hasil uji realibilitas pada output SPSS dapat dilihat pada tabel 2.

Tabel 1. Hasil UJi Validitas

\begin{tabular}{|l|c|c|c|c|c|}
\hline & $\begin{array}{c}\text { Scale Mean if } \\
\text { Item Deleted }\end{array}$ & $\begin{array}{c}\text { Scale Variance } \\
\text { if Item Deleted }\end{array}$ & $\begin{array}{c}\text { Corrected } \\
\text { Item-Total } \\
\text { Correlation }\end{array}$ & $\begin{array}{c}\text { Squared } \\
\text { Multiple } \\
\text { Correlation }\end{array}$ & $\begin{array}{c}\text { Cronbach's } \\
\text { Alpha if Item } \\
\text { Deleted }\end{array}$ \\
\hline Pendapatan Keluarga & 1.168 .097 & $5.366 \mathrm{E} 10$ & .738 & .732 & .000 \\
Alokasi waktu kerja & 3.713 .442 & $5.413 \mathrm{E} 11$ & .810 & .685 & .439 \\
Pendapatan wanita & 2.545 .875 & $2.327 \mathrm{E} 11$ & .738 & .639 & .000 \\
Pendidikan Wanita & 3.713 .671 & $5.413 \mathrm{E} 11$ & .733 & .599 & .439 \\
JumlahTanggungan & 3.713 .674 & $5.413 \mathrm{E} 11$ & .490 & .277 & .439 \\
Keluarga & 3.713 .670 & $5.413 \mathrm{E} 11$ & .249 & .417 & .439 \\
Lama Bekerja & 3.713 .634 & $5.413 \mathrm{E} 11$ & .211 & .447 & .439 \\
\hline
\end{tabular}


Tabel 2 Reliability Statistics (Hasil Uji Realibility)

\begin{tabular}{|c|c|c|}
\hline Cronbach's Alpha & Cronbach's Alpha Based on Standardized Items & N of Items \\
\hline .688 & .910 & 4 \\
\hline
\end{tabular}

Berdasarkan tabel 2 kita ketahui nilai Cronbach's Alpha Based on Standardized Items pada output SPSS tabel reliability statistics memiliki nilai lebih besar dari 0.60. Maka dapat dinyatakan semua variabel adalah reliabel.

\section{Uji Multikolineritas}

Untuk mengetahui ada tidaknya variabel independen yang memiliki kemiripan dengan variabel independen lain, dilakukan uji multikolineritas. Uji ini juga dilakukan untuk menghindari kebiasan dalam proses pengambilan kesimpulan mengenai pengaruh pada uji parsial masing-masing variabel independen terhadap variabel dependen. Hasil uji multikolineritas pada output SPSS dapat dilihat pada tabel 3.

Berdasarkan tabel 3 kita ketahui nilai Variance Inflation Factor (VIF) pada output SPSS tabel Coefficientts, masingmasing variabel independent memiliki VIF tidak lebih dari 10 dan nilai toleransi tidak kurang dari 0.1. Maka dapat dinyatakan semua variabel terbebas dari multikolineritas.

\section{Tabel 3. Hasil Uji Multikolinearitas}

\begin{tabular}{|c|c|c|c|c|c|c|c|}
\hline \multirow[b]{2}{*}{ Model } & \multicolumn{2}{|c|}{$\begin{array}{l}\text { Unstandardized } \\
\text { Coefficients }\end{array}$} & \multirow{2}{*}{$\begin{array}{c}\begin{array}{c}\text { Standardized } \\
\text { Coefficients }\end{array} \\
\text { Beta }\end{array}$} & \multirow[b]{2}{*}{$\mathrm{t}$} & \multirow[b]{2}{*}{ Sig. } & \multicolumn{2}{|c|}{$\begin{array}{l}\text { Collinearity } \\
\text { Statistics }\end{array}$} \\
\hline & B & Std. Error & & & & Tolerance & VIF \\
\hline 1 (Constant) & 168.134 & 399.413 & & .421 & .676 & & \\
\hline Alokasi waktu kerja & 4.088 & 1.951 & .297 & 2.096 & .043 & .352 & 2.843 \\
\hline Pendapatan Wanita & .581 & .275 & .279 & 2.110 & .042 & .403 & 2.479 \\
\hline Pendidikan & 42.680 & 20.039 & .267 & 2.130 & .040 & .449 & 2.225 \\
\hline $\begin{array}{l}\text { Jumlah tanggungan } \\
\text { Keluarga }\end{array}$ & 62.080 & 29.745 & .195 & 2.087 & .044 & .806 & 1.240 \\
\hline LamaBekerja & 12.058 & 9.606 & .135 & 1.255 & .217 & .607 & 1.647 \\
\hline Umur & 7.816 & 6.257 & .138 & 1.249 & .219 & .576 & 1.737 \\
\hline
\end{tabular}




\section{Uji Heteroskesdastisitas}

Untuk menguji terjadinya perbedaan variance residual suatu periode pengamatan ke periode pengamatan yang lain atau gambaran hubungan antara nilai yang diprediksi dengan studenttized delete regresi maka digunakan $\mathrm{Uji}$ Heteroskesdastisitas. Cara memprediksi ada tidaknya heteroskesdastisitas pada suatu model dapat dilihat dari pola gambar 1.

Dari gambar 1 dapat dilihat, titik-titik data menyebar diatas dan dibawah atau disekitar angka 0, titik-titik data tidak mengumpul hanya diatas atau dibawah saja, penyebaran titik-titik data tidak membentuk pola bergelombang melebar kemudian menyempit dan melebar kembali. Kemudian penyebaran titik-titik data tidak berpola sehingga dapat dikatakan semua variabel terbebas dari heteroskesdastisitas.

\section{Pengaruh Alokasi Waktu Kerja wanita penyadap karet Terhadap Pendapatan}

\section{Keluarga}

Hasil analisis regresi linear sederhana antara alokasi waktu kerja $\left(\mathrm{X}_{1}\right)$, terhadap pendapatan keluarga (Y). Hasil T-test menunjukkan independent secara parsial berpengaruh terhadap variabel dependent jika p-value (pada kolom Sig.) lebih kecil dari level of significant yang ditentukan (0.05) atau T hitung (pada kolom T) lebih besar dari $\mathrm{T}$ tabel. Hasil $\mathrm{T}$-test pada output SPSS dapat dilihat pada tabel 4.

Scatterplot

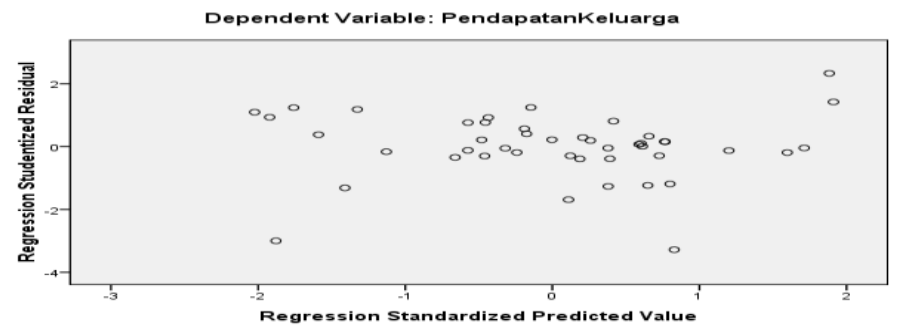

Gambar 1. Scatterplot

Tabel 4 Hasil T-test Alokasi Waktu Kerja

\begin{tabular}{|c|c|c|c|c|c|}
\hline \multirow[b]{2}{*}{ Model } & \multicolumn{2}{|c|}{$\begin{array}{c}\text { Unstandardized } \\
\text { Coefficients }\end{array}$} & \multirow{2}{*}{$\begin{array}{c}\begin{array}{c}\text { Standardized } \\
\text { Coefficients }\end{array} \\
\text { Beta }\end{array}$} & \multirow[b]{2}{*}{$\mathrm{t}$} & \multirow[b]{2}{*}{ Sig. } \\
\hline & B & Std. Error & & & \\
\hline (Constant) & 48.908 & 318.924 & & .153 & .879 \\
\hline $\begin{array}{c}\text { Alokasi Waktu } \\
\text { Kerja }\end{array}$ & 10.609 & 1.340 & .770 & 7.913 & .000 \\
\hline
\end{tabular}

a. Dependent Variabel: Pendapatan Keluarga 
Output SPSS tersebut menunjukkan $p$ value (0.000) lebih kecil dari level of significant yang ditentukan (0.05), artinya signifikan. Sedangkan t hitung sebesar 7.91 lebih besar dari t tabel yaitu 2.02 (df $=45-1=44)$, artinya signifikan berarti Ha diterima dan Ho ditolak artinya alokasi waktu kerja $\left(\mathrm{X}_{1}\right)$, berpengaruh terhadap pendapatan keluarga (Y).

Kemudian untuk mengetahui seberapa besar kemampuan variabel independen (alokasi waktu kerja) menjelaskan variabel dependent secara parsial berpengaruh terhadap pendapatan keluarga dilakukan uji koefisien determinasi. Dalam Output SPSS, koefisien determinasi terletak pada tabel model summary dan tertulis $R$ Square. Nilai Square dikatakan baik jika diatas 0,5 karena nilai $\mathrm{R}$ Square berkisar antara 0 sampai 1 (Nugroho. B, 2005). Hasil koefisien determinasi pada output SPSS dapat dilihat pada tabel 5 .

Dari hasil estimasi diperoleh nilai koefisien determinasi $\left(\mathrm{R}^{2}\right)$ sebesar 0.59 atau sebesar 59\%. Sisanya sebesar $41 \%$ dijelaskan oleh variabel lain yang tidak ada pada model tersebut. Jadi besarnya pengaruh alokasi waktu kerja wanita penyadap karet $\left(\mathrm{X}_{1}\right)$ adalah sebesar $59 \%$.

\section{Pengaruh Pendapatan wanita penyadap karet Terhadap Pendapatan}

\section{Keluarga}

Berdasarkan hasil analisis regresi linear sederhana antara pendapatan wanita penyadap karet $\left(\mathrm{X}_{2}\right)$, terhadap pendapatan keluarga (Y). Hasil T-test pada output SPSS dapat dilihat pada tabel 6.

Output SPSS pada tabel 6 menunjukkan p-value (0.000) lebih kecil dari level of significant yang ditentukan (0.05), artinya signifikan. Sedangkan t hitung sebesar 7.18 lebih besar dari t tabel yaitu 2.02 (df $=45-1=44)$, artinya signifikan berarti Ha diterima dan Ho ditolak artinya pendapatan wanita penyadap karet $\left(\mathrm{X}_{2}\right)$, berpengaruh terhadap pendapatan keluarga (Y).

\section{Tabel 5 Hasil Koefisien Determinasi Alokasi Waktu Kerja wanita penyadap} karet

\begin{tabular}{|c|c|c|}
\hline R Square & Adjusted R Square & Std. Error of the Estimate \\
\hline .593 & .583 & 311.336 \\
\hline
\end{tabular}

a. Predictors: (Constant), Alokasi Waktu Kerja 
Tabel 6 Hasil T-test Pendapatan wanita penyadap karet

\begin{tabular}{|cc|c|c|c|c|c|}
\hline \multirow{2}{*}{} & \multicolumn{2}{|c|}{$\begin{array}{c}\text { Unstandardized } \\
\text { Coefficients }\end{array}$} & $\begin{array}{c}\text { Standardized } \\
\text { Coefficients }\end{array}$ & & \\
\cline { 2 - 5 } & Model & $\mathrm{B}$ & Std. Error & Beta & $\mathrm{T}$ & Sig. \\
\hline 1 & $\begin{array}{c}\text { (Constant) } \\
\text { Pendapatan wanita } \\
\text { penyadap karet }\end{array}$ & 1.538 & .214 & .738 & 7.179 & .000 \\
\hline
\end{tabular}

a. Dependent Variable: Pendapatan Keluarga

Untuk mengetahui seberapa besar kemampuan variabel independen (pendapatan wanita penyadap karet) menjelaskan variabel dependent secara parsial berpengaruh terhadap pendapatan keluarga dilakukan uji koefisien determinasi. Hasil koefisien determinasi pada output SPSS dapat dilihat pada tabel 7.

Berdasarkan tabel 7, diperoleh nilai koefisien determinasi $\left(\mathrm{R}^{2}\right)$ sebesar 0.54 atau sebesar $54 \%$. sisanya sebesar $46 \%$ dijelaskan oleh variabel lain yang tidak ada pada model tersebut. Jadi besarnya pengaruh pendapatan wanita penyadap karet $\left(\mathrm{X}_{2}\right)$ adalah sebesar $54 \%$.

\section{Pengaruh Pendidikan wanita} penyadap karet Terhadap Pendapatan

\section{Keluarga}

Berdasarkan hasil analisis regresi linear sederhana antara pendidikan wanita penyadap karet $\left(\mathrm{X}_{3}\right)$, terhadap pendapatan keluarga (Y). Hasil T-test pada output SPSS dapat dilihat pada tabel 8 .

Berdasarkan tabel 8, menunjukkan $p$ value (0.000) lebih kecil dari level of significant yang ditentukan (0.05), artinya signifikan. Sedangkan $\mathrm{t}$ hitung sebesar 6.62 lebih besar dari t tabel yaitu 2.02 (df $=45-1=44$ ), artinya signifikan berarti Ha diterima dan Ho ditolak artinya pendidikan $\left(\mathrm{X}_{3}\right)$, berpengaruh terhadap pendapatan keluarga (Y).

Tabel 7 Koefisien Determinasi Pendapatan wanita penyadap karet

\begin{tabular}{|c|c|c|c|c|}
\hline Model & $\mathrm{R}$ & $\mathrm{R}$ Square & Adjusted R Square & Std. Error of the Estimate \\
\hline 1 & $.738^{\mathrm{a}}$ & .545 & .535 & 329.060 \\
\hline
\end{tabular}

a. Predictors: (Constant), Pendapatan wanita penyadap karet 
Tabel 8 Hasil T-test Pendidikan wanita penyadap karet

\begin{tabular}{|l|c|c|c|c|c|}
\hline \multirow{2}{*}{ Model } & \multicolumn{2}{|c|}{$\begin{array}{c}\text { Unstandardized } \\
\text { Coefficients }\end{array}$} & $\begin{array}{c}\text { Standardized } \\
\text { Coefficients }\end{array}$ & & \\
\cline { 2 - 5 } & $\mathrm{B}$ & Std. Error & Beta & $\mathrm{T}$ & Sig. \\
\hline $1 \quad \begin{array}{l}\text { (Constant) } \\
\begin{array}{l}\text { Pendidikan wanita } \\
\text { penyadap karet }\end{array}\end{array}$ & $1.826 \mathrm{E} 6$ & 120.159 & & 15.194 & .000 \\
\hline
\end{tabular}

a. Dependent Variable: Pendapatan Keluarga

Selanjutnya untuk mengetahui seberapa besar kemampuan variabel independen (pendidikan) menjelaskan variabel dependent secara parsial berpengaruh terhadap pendapatan keluarga dilakukan uji koefisien determinasi. Hasil koefisien determinasi pada output SPSS dapat dilihat pada tabel 9 .

Berdasarkan tabel 9, diperoleh nilai koefisien determinasi $\left(\mathrm{R}^{2}\right)$ sebesar 0.50 atau sebesar $50 \%$. sisanya sebesar $50 \%$ dijelaskan oleh variabel lain yang tidak ada pada model tersebut. Jadi besarnya pengaruh pendidikan wanita penyadap karet (X3) adalah sebesar 50\%.

\section{Pengaruh Jumlah Tanggungan Wanita}

Penyadap Karet terhadap Pendapatan

\section{Keluarga}

Berdasarkan hasil analisis regresi linear sederhana antara jumlah tanggungan wanita penyadap karet $\left(\mathrm{X}_{4}\right)$, terhadap pendapatan keluarga (Y). Hasil T-test pada output SPSS dapat dilihat pada tabel 10.
Berdasarkan tabel 10, menunjukkan $p$ value (0.000) lebih kecil dari level of significant yang ditentukan (0.05), artinya signifikan. Sedangkan t hitung sebesar 3.90 lebih besar dari t tabel yaitu 2.02 (df $=45-1=44$ ), artinya signifikan berarti Ha diterima dan Ho ditolak artinya jumlah tanggungan $\left(\mathrm{X}_{4}\right)$, berpengaruh terhadap pendapatan keluarga (Y).

Selanjutnya untuk mengetahui seberapa besar kemampuan variabel independen (jumlah tanggungan) menjelaskan variabel dependent secara parsial berpengaruh terhadap pendapatan keluarga dilakukan uji koefisien determinasi. Hasil koefisien determinasi pada output SPSS dapat dilihat pada tabel 11 .

Berdasarkan tabel diatas, diperoleh nilai koefisien determinasi $\left(\mathrm{R}^{2}\right)$ sebesar 0.26 atau sebesar $26 \%$. sisanya sebesar $74 \%$ dijelaskan oleh variabel lain yang tidak ada pada model tersebut. Jadi besarnya pengaruh jumlah tanggungan wanita penyadap karet $\left(\mathrm{X}_{4}\right)$ adalah sebesar $26 \%$. 
Tabel 9 Koefisien Determinasi Pendidikan wanita penyadap karet

\begin{tabular}{|l|r|r|r|r|}
\hline Model & \multicolumn{1}{|c|}{ R } & R Square & Adjusted R Square & Std. Error of the Estimate \\
\hline 1 & $.711^{\mathrm{a}}$ & .505 & .493 & 343.311 \\
\hline
\end{tabular}

a. Predictors: (Constant), Pendidikan wanita penyadap karet

Tabel 10 Hasil T-test Jumlah Tanggungan wanita penyadap karet

\begin{tabular}{|c|c|c|c|c|c|}
\hline \multirow[b]{2}{*}{ Model } & \multicolumn{2}{|c|}{ Unstandardized Coefficients } & \multirow{2}{*}{$\begin{array}{c}\begin{array}{c}\text { Standardized } \\
\text { Coefficients }\end{array} \\
\text { Beta }\end{array}$} & \multirow[b]{2}{*}{$\mathrm{t}$} & \multirow[b]{2}{*}{ Sig. } \\
\hline & $\mathrm{B}$ & Std. Error & & & \\
\hline (Constant) & $1.982 \mathrm{E} 6$ & 157447.122 & & 12.588 & .000 \\
\hline $\begin{array}{c}\text { Jumlah Tanggungan } \\
\text { Keluarga }\end{array}$ & 162599.012 & 41684.392 & .511 & 3.901 & .000 \\
\hline
\end{tabular}

a. Dependent Variable: Pendapatan Keluarga

Tabel 11 Koefisien Determinasi Jumlah Tanggungan wanita penyadap karet

\begin{tabular}{|c|c|c|c|c|}
\hline Model & $\mathrm{R}$ & R Square & $\begin{array}{c}\text { Adjusted R } \\
\text { Square }\end{array}$ & Std. Error of the Estimate \\
\hline 1 & $.511^{\mathrm{a}}$ & .261 & .244 & 419.337 \\
\hline
\end{tabular}

a. Predictors: (Constant), Jumlah Tanggungan Keluarga

b. Dependent Variable: Pendapatan Keluarga

\section{Pengaruh Lama Bekerja wanita} penyadap karet Terhadap Pendapatan

\section{Keluarga}

Berdasarkan hasil analisis regresi linear sederhana antara lama bekerja wanita penyadap karet $\left(\mathrm{X}_{5}\right)$, terhadap pendapatan keluarga (Y). Hasil T-test pada output SPSS dapat dilihat pada tabel 12.

Output SPSS tersebut menunjukkan $p$ value (0.000) lebih besar dari level of significant yang ditentukan (0.05), artinya tidak signifikan. Sedangkan $t$ hitung sebesar 1.58 lebih kecil dari t tabel yaitu $2.02(\mathrm{df}=45-1=44)$, artinya berarti Ho diterima dan $\mathrm{Ha}$ ditolak artinya lama bekerja $\left(\mathrm{X}_{5}\right)$, tidak berpengaruh terhadap pendapatan keluarga $(\mathrm{Y})$.

\section{Pengaruh Umur wanita penyadap} karet Terhadap Pendapatan Keluarga

Berdasarkan hasil analisis regresi linear sederhana antara umur wanita penyadap karet $\left(\mathrm{X}_{6}\right)$, terhadap pendapatan keluarga (Y). Hasil T-test pada output SPSS dapat dilihat pada tabel 13 . 
Tabel 12 Hasil T-test Lama Bekerja wanita penyadap karet

\begin{tabular}{|l|c|c|c|c|c|}
\hline \multirow{2}{*}{ Model } & \multicolumn{2}{|c|}{$\begin{array}{c}\text { Unstandardized } \\
\text { Coefficients }\end{array}$} & $\begin{array}{c}\text { Standardized } \\
\text { Coefficients }\end{array}$ & \multirow{2}{*}{ Sig. } \\
\cline { 2 - 5 } & $\mathrm{B}$ & Std. Error & Beta & $\mathrm{t}$ & .000 \\
\hline $1 \quad \begin{array}{l}\text { (Constant) } \\
\text { Lama } \\
\text { Bekerja }\end{array}$ & $2.695 \mathrm{E} 6$ & 118.304 & & 22.784 & .121 \\
\hline
\end{tabular}

a. Dependent Variable: Pendapatan Keluarga

Tabel 13 Hasil T-test Umur wanita penyadap karet

\begin{tabular}{|c|c|c|c|c|c|}
\hline \multirow[b]{2}{*}{ Model } & \multicolumn{2}{|c|}{ Unstandardized Coefficients } & \multirow{2}{*}{$\begin{array}{c}\begin{array}{c}\text { Standardized } \\
\text { Coefficients }\end{array} \\
\text { Beta }\end{array}$} & \multirow[b]{2}{*}{$\mathrm{t}$} & \multirow[b]{2}{*}{ Sig. } \\
\hline & B & Std. Error & & & \\
\hline 1 (Constant) & $2.960 \mathrm{E} 6$ & 374.398 & & 7.906 & .000 \\
\hline Umur & 9.578 & 8.497 & .169 & 1.127 & .266 \\
\hline
\end{tabular}

a. Dependent Variable: Pendapatan Keluarga

Output SPSS pada tabel 13 menunjukkan p-value (0.000) lebih besar dari level of significant yang ditentukan (0.05), artinya tidak signifikan. Sedangkan $t$ hitung sebesar 1.13 lebih kecil dari t tabel yaitu $2.02(\mathrm{df}=45-1=44)$, artinya Ho diterima dan Ha ditolak artinya umur $\left(\mathrm{X}_{6}\right)$, tidak berpengaruh terhadap pendapatan keluarga (Y).

Pengaruh Alokasi Waktu Kerja, Pendapatan wanita penyadap karet, Pendidikan, Jumlah Tanggungan, Lama Bekerja dan Umur Secara Bersama-sama Terhadap Pendapatan Keluarga

Hasil analisis regresi linear berganda antara alokasi waktu kerja $\left(\mathrm{X}_{1}\right)$, pendapatan wanita penyadap karet $\left(\mathrm{X}_{2}\right)$, pendidikan wanita penyadap karet $\left(\mathrm{X}_{3}\right)$ jumlah tanggungan $\left(\mathrm{X}_{4}\right)$, lama bekerja $\left(\mathrm{X}_{5}\right)$ dan umur wanita penyadap $\operatorname{karet}\left(\mathrm{X}_{6}\right)$ sebagai variabel independent terhadap pendapatan keluarga (Y). Hasil F-test menunjukkan variable independent secara bersama-sama berpengaruh terhadap variabel dependent jika p-value (pada kolom Sig.) lebih kecil dari level of significant yang ditentukan (0.05) atau $\mathrm{F}$ hitung (pada kolom F) lebih besar dari F tabel. Hasil F-test pada output SPSS dapat dilihat pada tabel 14 .

Output SPSS tersebut menunjukkan $p$ value (0.000) lebih kecil dari level of significant yang ditentukan (0.05), artinya signifikan. Sedangkan F hitung sebesar 
17.30 lebih besar dari $\mathrm{F}$ tabel 2.85 (df $1=$ $7-1=8$ dan df $2=45-7=38$ ), artinya signifikan berarti $\mathrm{Ha}$ diterima dan $\mathrm{Ho}$ ditolak artinya alokasi waktu kerja, pendapatan wanita penyadap karet, pendidikan, jumlah tanggungan, lama bekerja dan umur wanita penyadap secara bersama-sama berpengaruh terhadap pendapatan keluarga.

Hasil koefisien determinasi pada output SPSS dapat dilihat pada tabel 15. Dari hasil estimasi diperoleh nilai koefisien determinasi $\left(\mathrm{R}^{2}\right)$ sebesar 0.69 atau sebesar 69\%. Dan sisanya sebesar 31\% dijelaskan oleh variabel lain yang tidak ada pada model tersebut. Jadi besarnya pengaruh alokasi waktu kerja $\left(\mathrm{X}_{1}\right)$, pendapatan wanita penyadap karet $\left(\mathrm{X}_{2}\right)$, pendidikan $\left(\mathrm{X}_{3}\right)$ jumlah tanggungan keluarga $\left(\mathrm{X}_{4}\right)$, lama bekerja $\left(\mathrm{X}_{5}\right)$ dan umur $\left(\mathrm{X}_{6}\right)$ secara bersama-sama adalah sebesar $69 \%$.

Untuk mengetahui pengaruh variabel independen yang mana yang mempengaruhi pendapatan keluarga, maka dapat dilakukan dengan menggunakan uji parsial terhadap kefisien regresi. Pengaruh masing-masing variabel independen terhadap variabel dependent tersebut secara jelas disajikan dalam tabel 16.

Tabel 14 ANOVA (F-hitung $X_{1}, X_{2}, X_{3}, X_{4}, X_{5}, X_{6}$ terhadap Y)

\begin{tabular}{|c|c|c|c|c|c|}
\hline Model & $\begin{array}{l}\text { Sum of } \\
\text { Squares }\end{array}$ & $\mathrm{df}$ & Mean Square & $\mathrm{F}$ & Sig. \\
\hline $1 \quad$ Regression & $7.494 \mathrm{E} 12$ & 6 & $1.249 \mathrm{E} 12$ & 17.302 & $.000^{\mathrm{a}}$ \\
\hline Residual & $2.743 \mathrm{E} 12$ & 38 & $7.219 \mathrm{E} 10$ & & \\
\hline Total & $1.024 \mathrm{E} 13$ & 44 & & & \\
\hline
\end{tabular}

a. Predictors: (Constant), Umur, Jumlah Tanggungan Keluarga, Pendapatan, Lama Bekerja, Pendidikan, Alokasi Waktu Kerja

b. Dependent Variable: Pendapatan Keluarga

Tabel 15 Koefisien Determinasi $X_{1}, X_{2}, X_{3}, X_{4}, X_{5}, X_{6}$ terhadap $Y$

\begin{tabular}{|c|c|c|c|c|c|}
\hline Model & $\mathrm{R}$ & R Square & $\begin{array}{c}\text { Adjusted R } \\
\text { Square }\end{array}$ & $\begin{array}{c}\text { Std. Error of } \\
\text { the Estimate }\end{array}$ & $\begin{array}{c}\text { Durbin- } \\
\text { Watson }\end{array}$ \\
\hline 1 & $.856^{\mathrm{a}}$ & .732 & .690 & 268.676 & 2.145 \\
\hline
\end{tabular}

a. Predictors: (Constant), Umur, Jumlah tanggungan Keluarga, Pendapatan, Lama Bekerja, Pendidikan, Alokasi waktu kerja

b. Dependent Variable: Pendapatan Keluarga 
Tabel 16 (T-hitung $X_{1}, X_{2}, X_{3}, X_{4}, X_{5}, X_{6}$ terhadap Y)

\begin{tabular}{|c|c|c|c|c|c|c|c|}
\hline \multirow[b]{2}{*}{ Model } & \multicolumn{2}{|c|}{$\begin{array}{l}\text { Unstandardized } \\
\text { Coefficients }\end{array}$} & \multirow{2}{*}{$\begin{array}{c}\begin{array}{c}\text { Standardized } \\
\text { Coefficients }\end{array} \\
\text { Beta }\end{array}$} & \multirow[b]{2}{*}{$\mathrm{t}$} & \multirow[b]{2}{*}{ Sig. } & \multicolumn{2}{|c|}{$\begin{array}{l}\text { Collinearity } \\
\text { Statistics }\end{array}$} \\
\hline & B & Std. Error & & & & Tolerance & VIF \\
\hline 1 (Constant) & 168.134 & 399.413 & & .421 & .676 & & \\
\hline Alokasi waktu kerja & 4.088 & 1.951 & .297 & 2.096 & .043 & .352 & 2.843 \\
\hline Pendapatan Wanita & .581 & 275 & .279 & 2.110 & .042 & .403 & 2.479 \\
\hline Pendidikan & 42.680 & 20.039 & .267 & 2.130 & .040 & .449 & 2.225 \\
\hline $\begin{array}{l}\text { Jumlah tanggungan } \\
\text { Keluarga }\end{array}$ & 62.080 & 29.745 & .195 & 2.087 & .044 & .806 & 1.240 \\
\hline LamaBekerja & 12.058 & 9.606 & .135 & 1.255 & .217 & .607 & 1.647 \\
\hline Umur & 7.816 & 6.257 & .138 & 1.249 & .219 & .576 & 1.737 \\
\hline
\end{tabular}

\section{Alokasi Waktu Kerja (X)}

Hasil analisis secara parsial antar alokasi waktu kerja wanita penyadap karet terhadap pendapatan keluarga diperoleh nilai t hitung lebih besar (2.09) dari nilai $\mathrm{t}$ tabel (2.02). Hal ini mengakibatkan Ho ditolak dan Ha diterima, artinya adalah terdapat pengaruh yang signifikan antara alokasi waktu kerja terhadap pendapatan keluarga.

\section{Pendapatan wanita penyadap karet} $\left(\mathbf{X}_{2}\right)$

Hasil analisis secara parsial (individual) antara pendapatan wanita penyadap karet terhadap pendapatan keluarga diperoleh nilai $\mathrm{t}$ hitung lebih besar (2.11) dari nilai $\mathrm{t}$ tabel (2.02). Hal ini mengakibatkan Ho ditolak dan Ha diterima, artinya adalah terdapat pengaruh yang signifikan antara alokasi waktu kerja terhadap pendapatan keluarga.
Pendidikan wanita penyadap karet $\left(\mathbf{X}_{3}\right)$

Pendidikan wanita penyadap karet berpengaruh signifikan terhadap pendapatan keluarga dengan nilai t hitung lebih besar (2.13) dari nilai t tabel (2.02) Hal ini mengakibatkan Ho ditolak dan $\mathrm{Ha}$ diterima, artinya adalah antara pendidikan wanita penyadap karet terhadap pendapatan keluarga terdapat pengaruh signifikan.

\section{Jumlah Tanggungan wanita penyadap karet $\left(\mathbf{X}_{4}\right)$}

Hasil analisis secara parsial (individual) antara jumlah tanggungan wanita penyadap karet terhadap pendapatan keluarga diperoleh nilai $\mathrm{t}$ hitung lebih besar (2.09) dari nilai t tabel (2.02). Hal ini mengakibatkan $\mathrm{Ho}$ ditolak dan $\mathrm{Ha}$ diterima, artinya adalah terdapat pengaruh yang signifikan antara jumlah tanggungan 
wanita penyadap karet terhadap pendapatan keluarga.

\section{Lama bekerja wanita penyadap karet} (X5)

Hasil analisis secara parsial (individual) antara lama bekerja wanita penyadap karet terhadap pendapatan keluarga diperoleh nilai t hitung lebih kecil (1.25) dari nilai $\mathrm{t}$ tabel (2.02). Hal ini mengakibatkan $\mathrm{Ha}$ ditolak dan $\mathrm{Ho}$ diterima, artinya tidak terdapat pengaruh yang signifikan antara lamanya bekerja wanita penyadap karet terhadap pendapatan keluarga.

\section{Umur wanita penyadap karet $\left(\mathbf{X}_{6}\right)$}

Hasil analisis secara parsial (individual) antara umur wanita penyadap karet terhadap pendapatan keluarga diperoleh nilai $\mathrm{t}$ hitung lebih kecil (1.25) dari nilai $\mathrm{t}$ tabel (2.02). Hal ini mengakibatkan $\mathrm{Ha}$ ditolak dan Ho diterima, artinya adalah tidak terdapat pengaruh yang signifikan antara umur wanita penyadap karet terhadap pendapatan keluarga.

\section{KESIMPULAN DAN SARAN}

Kesimpulan

Berdasarkan hasil wawancara dan observasi di lapangan yang telah dilakukan, maka dapat disimpulkan sebagai berikut :
1. Hasil analisis regresi linear sederhana antara alokasi waktu kerja wanita penyadap karet terhadap pendapatan terdapat pengaruh yang signifikan terhadap pendapatan keluarga, yaitu sebesar $59 \%$.

2. Pendapatan wanita penyadap karet berpengaruh secara signifikan terhadap pendapatan keluarga, yaitu sebesar 54\%.

3. Pendidikan wanita penyadap karet berpengaruh secara signifikan dengan pendapatan keluarga, yaitu sebesar $50 \%$.

4. Jumlah tanggungan wanita penyadap karet terhadap pendapatan keluarga terdapat pengaruh yang signifikan, yaitu sebesar $26 \%$.

5. Lama bekerja wanita penyadap karet tidak terdapat pengaruh yang signifikan terhadap pendapatan keluarga

6. Umur wanita penyadap karet tidak terdapat pengaruh yang signifikan terhadap pendapatan keluarga.

7. Hasil analisis regresi linear berganda antara variabel independent (alokasi waktu kerja, pendapatan wanita penyadap karet, pendidikan wanita penyadap karet, jumlah tanggungan keluarga, lama bekerja 
dan umur berpengaruh terhadap variabel dependent yaitu pendapatan keluarga, sebesar sebesar $69 \%$.

\section{Saran}

1. Alokasi waktu kerja wanita penyadap karet masih banyak yang belum maksimal, seperti pada saat menunggu getah karet terkumpul. Untuk itu disarankan perlu dilakukan pemberdayaan, sehingga mereka memiliki keterampilan pada saat menunggu getah karet tersebut, pada akhirnya waktu dapat maksimal digunakan untuk meningkatkan pendapatan keluarga.

2. Pendidikan wanita penyadap karet perlu ditingkatkan, karena dengan pengetahuan dan keterampilan yang meningkat, lebih mudah bagi wanita penyadap untuk memperoleh pekerjaan diluar sebagai penyadap, sehingga kebutuhan dapat terpenuhi.

3. Banyaknya jumlah anggota rumah tangga mendorong wanita semakin banyak menggunakan tenaganya pada kegiatan-kegiatan yang dapat memberikan tambahan pendapatan. Untuk itu perlu dilakukan pembagian tugas di dalam keluarga agar beban dari orang tua atau istri dapat berkurang.

4. Pada umumnya wanita penyadap karet belum lama bekerja, namun perlu dilakukan peningkatan pengalaman dalam hal menyadap karet, sehingga resiko-resiko (luka kecil, gatal-gatal) yang terjadi di lapangan bisa di kurangi.

5. Secara bersamaan besarnya pengaruh variabel $\mathrm{x}$ terhadap pendapatan keluarga yaitu sebesar $69 \%$. Jadi masih $31 \%$ variabel yang lain, yang belum terungkap dalam penelitian ini, untuk itu disarankan kepada peneliti yang lain untuk lebih mengembangkan dan mengungkapkan variabel yang belum diteliti.

\section{DAFTAR PUSTAKA}

Alatas, Secha. 1990. The effect of change in life cycle strage on the migration behavior of individual in Javanese communities Indonesia. $\mathrm{PhD}$ Disertation. Brown University.

Anne Ahira. 2012. Pengertian Kontribusi. http://w.anneahira.com/kontribusi. html._Diambil tanggal 20 Mei 2016.

Arikunto, Suharsimi. 2005. Manajemen Penelitian. Rineka Cipta. Jakarta.

Eliana, N dan Ratina, R. 2006, FaktorFaktor Yang Mempengaruhi Curahan Waktu Kerja Wanita Pada PT Agricinal Samarinda. Jurusan Sosial Ekonomi, Fakultas Pertanian. Mulawarman. Samarinda 
Elizabeth, R. 2007, Pemberdayaan Wanita Mendukung Pembangunan di Pedesaan. Pusat Analisis Sosial Ekonomi dan Kebijakan Pertanian. Bogor.

Handayani M Th dan Artini Ni W P, 2009. Kontribusi Pendapatan Ibu Rumah Tangga Pembuat Makanan Olahan Terhadap Pendapatan Keluarga. Piramida Vol V No. 1.

Haryanto, S. 2008. Peran Aktif Wanita Dalam Peningkatan Pendapatan Rumah Tangga Miskin: Studi Kasus Pada Wanita Pemecah Batu Pucanganak Kecamatan Tugu Trenggalek. Jurnal Ekonomi Pembangunan volume 9 No 2 . Desember 2008, hal. 216-227. Universitas merdeka Malang. Malang.

Hermanto, 1994.http/www.Aspek-Aspek Pendapatan Ekonomi. Badan Penelitian dan pengembangan Pertanian. Jakarta. Diakses 16 Mei 2016.

Herwanto. 2002. Variabel-Variabel yang Mempengaruhi Jam Kerja Ibu Rumah Tangga Yang Bekerja Sebagai Pedagang Sayuran Keliling Di Desa Bululawang Kabupaten Malang. Skripsi. Fakultas Ekonomi. Universitas Rawijaya. Malang. Tidak dipublikasikan.

Mosher AT. 1987. Menggerakkan Dan Membangun Pertanian. Bina Aksara. Jakarta.

Mudiyono, dkk, 2005. Dimensi-Dimensi Masyarakat dan Pemberdayaan Masyarakat.

APMD Pres.Yogyakarta.

Mulyati, D dan Setiawan, D. 2006. Identifikasi Faktor Pendorong Bagi Ibu Rumah Tangga Dalam Merealisasikan Minat Usaha Menjadi Suatu Kegiatan Usaha (Studi Kasus : 12 Ibu Rumah Tangga Di Wilayah Bumi Serpong Damai Tangerang). Master Thesis from JBPTSBMITB. Institrut Teknologi Bandung. Bandung.

Pratiwi, H. 2011. Peran Perempuan Untuk Pendapatan Keluarga Makin

Signifikan.http://femalekompas.co $\mathrm{m} / \mathrm{read} / 2016 / 05 / 17 / 094 /$ peranpere mpuan untuk pendapatan keluarga. Diakses pada tanggal 17 April 2016.

Sajogjo, Pujiwati. 2009. Beberapa Aspek Pokok Yang Perlu Diperhatikan Dalam Proses Peningkatan Peran Wanita Di Pedesaan Dan Pengambilan Keputusan: Suatu Analisa Sosial Ekonomi. Cipayung.

Sajogyo (2002). Teknologi dan peluang kerja wanita di pedesaan. CV Rajawali. Jakarta

Sugeng Haryanto, 2009. Peran Aktif Wani ta Dalam Meningkatkan Pendapat an Rumah Tangga Miskin. Model Ekonomi Rumah Tangga Miskin. Jakarta.

Sukiyono, Ketut dan Sriyoto, 1997. Transformasi Struktural Wanita Transmigran Dan Kontribusinya Terhadap Pendapatan Rumah Tangga: kasus Di Daerah Transmigrasi Sekitar Kotamadya Bengkulu. Jurnal Agro Ekonomi Volume 16 No.1 dan 2 Oktober 1997. Fakultas Pertanian. Universitas Bengkulu. Bengkulu.

Sumarsono, dkk, 1995. Peranan Wanita Nelayan Dalam Kehidupan Keluarga di Kabupaten Tegal Provinsi Jawa Tengah. PT. Eka Putri. Jakarta.

Sumiati, Mulyaningsih dan Rofiaty. 2000. Wanita dari Sektor Informal : Peranan dan Kedudukannya dalam Rumahtangga. Jurnal Ilmu-ilmu Sosial Vol 12 No. 2. Jakarta.

Suradisastra, K dan lubis, M. 2000. Aspek Gender dalam Kegiatan Usaha Peternakan, Wartazoa 10.1. Pusat 
Penelitian sosial Ekonomi. Pendidikan Nasional 2003.

Pertanian. Bogor.

Undang-undang Republik Indonesia No.

20 Tahun 2003. Tentang Sistem http://samudrastudio.com.diakses

16

mei

2016. 